\title{
Peertechz
}

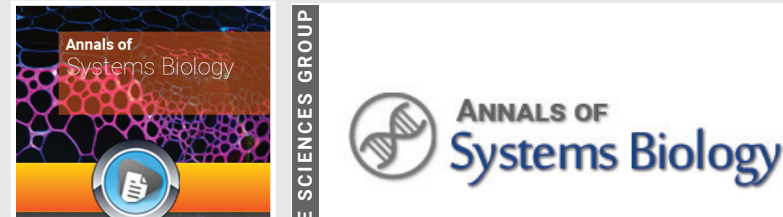

\section{The role of toll like receptor 9 in maintaining gut homeostasis}

\author{
Matthew G Varga ${ }^{1}$ and Henry C Lin ${ }^{2 *}$ \\ ${ }^{1}$ Biomedical Research Institute of New Mexico, Albuquerque, NM 87108, USA \\ ${ }^{2}$ Medicine Service, New Mexico VA Health Care System and Division of Gastroenterology and \\ Hepatology, Department of Internal Medicine, University of New Mexico, Albuquerque, NM 87131, USA
}

Received: 26 February, 2020

Accepted: 26 March, 2020

Published: 28 March, 2020

*Corresponding author: Henry C Lin, MD, Medicine Service, New Mexico VA Health Care System and Division of Gastroenterology and Hepatology, Department of Internal Medicine, University of New Mexico, New Mexico VA Health Care System 1501 San Pedro Dr. SE Albuquerque, NM 87108 Albuquerque, NM 87131 USA, Tel: (505)-265-1711 ext. 4552;

E-mail:Helin@salud.unm.edu

Keywords: TLR9; Intestinal homeostasis; Bacteriophage

https://www.peertechz.com

Check for updates

\section{Abstract}

Toll-Like Receptor 9 (TLR9) is a unique pattern recognition receptor due to its ability to induce either pro- or anti-inflammatory cascades. However, much remains to be elucidated regarding this receptor, such as its localization in different cell and tissue types, the potential epitopes that induce signaling, and how activation of the receptor may result in diverging pathways. Despite these unknowns, the integral role of TLR9 in maintaining gut homeostasis remains clear. In addition to maintaining homeostasis, TLR9 may also have significant potential in treating gut-associated inflammatory diseases such as ulcerative colitis, Crohn's and inflammatory bowel disease via its anti-inflammatory effects. This review will outline some of the key remaining questions regarding the role TLR9 in the gut and highlight its potential utility as a therapeutic target for gastrointestinal disease.

\section{Introduction}

The mucosal surfaces of the alimentary tract are perpetually challenged by antigens from environmental, dietary, microbial, and host-cell origins; any number of which have the capability of disrupting the relationship of the host with the delicate homeostatic environment of the gut. Yet, despite this perpetual bombardment, the immune response remains tightly controlled and poised to respond only to potential threats while remaining tolerant to the continuous presentation of foreign substances within the gut lumen.

Intestinal Epithelial Cells (IECs) line the lumen of the small intestine and colon in a single layer, separating the gut luminal contents from the sterile environment of the lamina propria. While the epithelium primarily acts as a physical barrier, it also plays an integral response in mediating innate immune responses to the luminal microbiota. Toll-Like Receptors (TLRs) are critical components of the IEC innate immune response through their detection of highly specific pathogen associated molecular patterns (PAMPs) [1]. Toll-Like Receptor 9 (TLR9) is one such receptor whose cognate ligand is hypomethylated $\mathrm{CpG}$ DNA motifs (microbial cytosine-guanine dinucleotide (CpG)-
DNA) [2], commonly found in bacterial and viral genomes. CpG/TLR9 refers then to the activation of TLR9 signaling by its cognate ligand. IECs are polarized, columnar cells with the apical surface facing the gut lumen and the basolateral surface facing the lamina propria. Both compartments of the IEC are highly specialized and serve distinct functions in maintaining gut homeostasis [3]. TLR9 is expressed in both compartments and serves dichotomous roles depending on the localization of its activation, whereby apical stimulation induces antiinflammatory responses and basolateral stimulation induces pro-inflammatory responses [3]. The apical, antiinflammatory responses can overcome pro-inflammatory signals transduced by other TLRs, highlighting the importance of TLR9 in maintaining gut homeostasis [3].

The microbiome in the large intestine is intimately associated with the IEC monolayer and thus regularly interacts with innate immune pattern recognition receptors without eliciting overt pro-inflammatory responses. This level of immune restraint, or tolerization, is due in large part to TLR9-mediated responses [4]. Thus, in this review, we seek to summarize the role of TLR9 in maintaining gut homeostasis in the face of the microbiome and how the utilization of this 
pathway may contribute to therapeutic interventions for certain inflammatory conditions of the gut.

\section{TLR9 localization and signaling in the gut}

TLR9 is usually considered an endosomal receptor expressed in a myriad of cell types, ranging from immunocytes to the mucosal epithelium [5]. However, consideration should be taken when comparing murine and human studies, as TLR9 detects different DNA epitopes between species and cellspecific expression is also different. Human TLR9 is limited to plasmacytoid Dendritic Cells (pDCs), neutrophils, B cells and the epithelium whilst mice share the same cellular expression pattern with the addition of macrophages and myeloid Dendritic Cells (mDCs) [2,6]. Within non-polarized cells such as dendritic cells, the endosomal trafficking system dictates the localization of TLR9 and its resultant signaling cascade [7]. Within these cell types, TLR9 engagement can result in one of two outcomes: either Interferon-Regulatory Factor (IRF)-mediated type 1 interferon or NF $\kappa \mathrm{B}$-mediated proinflammatory signaling [7]. Current studies are still examining the mechanisms by which this bifurcated pathway is regulated and the chaperone proteins involved in localizing TLR9 to specific endosomal subtypes [8].

While the exact signaling pathway of TLR9 in dendritic cells remains to be elucidated, even less is known regarding TLR9 in the polarized epithelium. Traditionally TLR9 was believed to be localized only within the endosome due to selective evolutionary pressure to hide TLR9 from identifying self- DNAs [9]. This hypothesis was tested in a murine model where the membrane localization domain of TLR9 was swapped with that of TLR4 to induce surface expression of TLR9. These transmembrane mutant mice died within 4 weeks due to systemic inflammation and anemia [10]. Furthermore, in an elegant study by Price, et al. the authors created novel, fluorescently tagged TLR reporter mice that were used to visualize the expression of individual TLRs in IECs. They found unique temporal and spatial expression of TLRs in the murine gut, notably that in the small intestine and colon, TLR9 is not expressed (or undetectably low) in the epithelium but abundantly expressed in the lamina propria [5]. The authors reasoned that expression may change during inflammation, and thus challenged the reporter mice with Dextran Sodium Sulfate (DSS) to induce colitis, or alternatively challenged mice with Salmonella Typhimurium. Neither challenge altered TLR9 expression from basal homeostatic conditions [5]. These results are mirrored in a cohort of Irritable Bowel Syndrome (IBS) patients who showed no significant changes in TLR9 mRNA expression in the jejunum or sigmoid colon compared to healthy controls [11]. In contrast, other in vitro and in vivo studies have shown that TLR9 could indeed be abundantly expressed on the surface of IECs and not limited to localization in endosomes $[2,3,12,13]$. Lee et al. demonstrated that TLR9 is expressed and also activated on both the apical and basolateral membrane surfaces of IECs and that the addition of chloroquine, an endosomal inhibitor, had no effect on TLR9 signaling, suggesting that TLR9 was in an active state when expressed on the cell surface in an endosomeindependent fashion [3]. Their study utilized polarized HCA7 and $\mathrm{CaCo}_{2}$ cell lines challenged with specific TLR9 agonists, and further demonstrated the unique pro- versus antiinflammatory signaling cascade resultant from stimulation in the basolateral versus apical compartment, respectively and that the anti-inflammatory effects of apical TLR9 stimulation could overcome pro-inflammatory responses induced by TLRs 2,3 or 5 [3]. The possibility that TLR9 expression is inducible and its variable expression may contribute to differences in the reported findings was suggested when TLR9 expression was reported to increase by DSS treatment. Transcriptional modulation of pattern recognition receptors in chronic colitis in mice is accompanied by Th1 and TH17 responses [14]. Site-specific expression of TLR9 is also more distinct in the small intestine than colon. Specifically, while small intestinal ordinary villi are immune-negative for TLR9, the roof of $\mathrm{M}$-cells of follicle-associated epithelium are immune-positive for TLR9 [15]. Taken together, these data suggest that cellspecific TLR9 expression may be constitutive or inducible and its function may be pro- or anti-inflammatory depending on whether the TLR9 examined is located on the surface or within the endosome. Thus, much remains to be elucidated regarding the expression, localization and localization-specific signaling cascades of this immunoregulatory receptor.

\section{TLR9 signaling in response to the gut microbiome}

While IECs present a physical barrier between the luminal microflora and the host, it also provides a platform that enables elaborate crosstalk between the microbiome and the immune response. TLRs have been shown to directly mediate the IEC response to the luminal microbiome via promoting the production of antimicrobial peptides and mucins which, in turn, promote gut barrier integrity [16]. Most TLRs are sequestered to the basolateral compartment of the epithelium or within the immune cells of the lamina propria $[16,17]$. This localizationspecific pattern of expression protects the host from aberrant immune activation and thus only mediates a response when the barrier has been penetrated. However, TLR9 represents an exception to the basolateral localization pattern, as some studies have shown that it is expressed at the apical surface of IECs and can promote anti-inflammatory signaling [3]. As such, TLR9 may act as a unique molecular rheostat which controls the appropriate level of inflammation to commensal microbes in the intestinal lumen (apical TLR9, anti-inflammatory) vs. those that translocate across the intestinal barrier (basolateral TLR9, pro-inflammatory). Such site-specific activation of differential TLR9 responses could potentially be useful in distinguishing between commensals and pathogens. In this regard, TLR9 can specifically determine the origin of DNA fragments to identify microbes as commensals versus pathogen and mount the appropriate response. Multiple studies have demonstrated the ability of probiotic bacterial DNAs to dampen the inflammatory response in both humans and mice [12,13,18-26]. Ewaschuk, et al. demonstrated that apical surface expression of TLR9 in IECs is up-regulated in response to pathogenic Salmonella DNA, while Katakura, et al. have proposed that probiotic DNA absorption in the small intestine and subsequent priming of TLR9+ immune cells may have systemic anti-inflammatory implications, such as amelioration of colitis [24]. This anti- 
inflammatory effect is mediated mostly by the production of type I IFNs from pDCs [24]. As the administration of CpG oligodeoxynucleotides before the induction of experimental colitis reduces the severity of inflammation [25], the antiinflammatory role of TLR9 was further confirmed by showing that a lack of $\mathrm{CpG} / \mathrm{TLR} 9$ interaction can significantly reduce the efficacy of immune-suppressive Helper $\mathrm{CD}_{4}{ }^{+} \mathrm{T}$ cells in the lamina propria of mice. Furthermore, that transplantation of $\mathrm{CD}_{4}{ }^{+} \mathrm{T}$ cells from those $\mathrm{Tlrg}^{-/-}$mice induced severe colitis in wild-type recipient mice [27].

Unlike other TLRs whose cognate ligands are unique to microbes, TLR9 detects DNA which is ubiquitous among all life. As such, TLR9 must be able to discriminate not only self from non-self DNA, but also between DNAs from commensal and potentially pathogenic bacteria or viruses. The mechanism by which TLR9 differentiates the origin of these molecules still remains to be elucidated. Multiple hypotheses have been proposed, including the detection of hypomethylated $\mathrm{CpG}$ motifs [28], (as DNA methylation occurs only on cytosine in eukaryotes [29], but primarily, on adenine in prokaryotes [30], the specificity of cellular uptake of select DNA molecules which are not degraded by host DNases [31], the structure of the DNA backbone [32-34], the sequence of the DNA fragment (immunoregulatory versus immunostimulatory sequences, IRS:ISS ratio) $[23,35]$ and the localization of TLR9 during DNA uptake [3]. Recently Ohto, et al. demonstrated that TLR9 has two DNA binding sites, a CpG motif binding site and a 5' $-\mathrm{xCx}$ motif, and that when both sites are bound they cooperatively activate signaling to a greater extent than CpG DNA alone [36].

As the cognate ligand of TLR9 is DNA, this suggests that its response need not be limited to bacterial members of the microbiome. In most microbial communities, including the gut, the number of bacteriophage (phage) vastly outnumber the bacterial populations by an order of magnitude [37] While most phage are sequestered within the bacterial host, studies have demonstrated that free phage can reside within the mucus layer and protect the gut barrier from invasive bacteria [38]. Intriguingly, a recent study by Gogokhia et al. has demonstrated that phage may also directly improve gut health via TLR9 signaling [39]. Although bacteriophage canno directly infect eukaryotic hosts, studies have shown that they can be transcytosed through epithelial cell lines, leaving the open possibility that they may engage immune cells, such as DCs, of the lamina propria in vivo. Gogokhia, et al. demonstrated that phage could directly stimulate IFN $\gamma$ production, and that this response was specifically due to phage DNA engagement of TLR9 [39].

\section{Clinical implications of TLR9 signaling in the gut}

As a unique regulator of both pro- and anti-inflammatory responses and its presence within a variety of cell types, TLR9 has gained traction as a possible receptor for therapeutic intervention of inflammatory diseases as well as adjuvant therapy in vaccine development.

The exact mechanism by which TLR9 detects DNAs remains to be elucidated, whether it is sequence or methylation dependent motifs, or tertiary structures/confirmations that confer the epitopes required for TLR9 binding and activation. Nonetheless, different types of DNAs (commensal origin, pathogenic, or self) confer unique signaling that can be exploited for therapeutic functions. Multiple studies have shown that administration of cell-free, probiotic DNAs can ameliorate the inflammation from DSS-induced colitis in mouse models $[18,21-24,40]$. This response is likely due to engagement of pDCs in the colon and the induction of type I IFNs. This anti-inflammatory response has also been obtained from the administration of synthetically derived Oligodeoxynucleotide (ODN) sequences as well as from pathogenic strains of $H$. pylori DNA $[23,35,41]$. The results of these studies were consistent despite different modes of administration, ranging from gavage and i.p. injections in mice to topical administration during endoscopy in humans $[22,24,42]$.

As research into phage therapy, particularly within the context of the microbiome, continues to grow, recent advances have shown the utility of TLR9 in promoting phage-based vaccine development. Bacteriophage have been used to present small fragments of pathogen epitopes without infecting eukaryotic cells to cultivate an immune response $[43,44]$. Once the antigen-displaying phage is endocytosed by pDCs, the phage DNA then activates TLR9 to induce strong cytokine production, DC maturation, and ultimately a protective immune response to the displayed antigen [43]. This method has proven successful in using filamentous $f d$ phage to develop a vaccine against $T$. cruzii in murine models [44]. However, TLR9 signaling may not always provide an adjuvant effect, as work with M13 phage has shown that TLR9 signaling dampens immune response, particularly in IgG1, IgG2b and IgG3 mediated responses [45]. These dichotomous results from different phage highlight both the exciting potential and highly nuanced applicability of phage therapy for vaccine design.

\section{Conclusions}

Despite the many unknowns surrounding TLR9, ranging from questions of its expression and localization, how it detects and discriminates between DNA ligands, to how it regulates unique and bifurcated signal transduction pathways in various cell types to be either pro- or anti-inflammatory- its critical role in establishing and maintaining gut homeostasis remains abundantly clear. Further research into this unique molecular rheostat will only prove to be fertile ground for potential therapeutics both within the gut and systemically.

\section{Acknowledgement}

The Winkler Bacterial Overgrowth Research Fund.

\section{References}

1. Varga MG, Peek RM (2017) DNA Transfer and Toll-like Receptor Modulation by Helicobacter pylori. Curr Top Microbiol Immunol 400: 169-193. Link: https://bit.ly/33Pthnz

2. Bauer S, Kirschning CJ, Hacker H, Redecke V, Hausmann S, et al. (2001) Human TLR9 confers responsiveness to bacterial DNA via species-specific CpG motif recognition. Proc Natl Acad Sci U S A 98: 9237-9242. Link: https://bit.ly/2QJiWEv

Citation: Varga MG, Lin HC (2020) The role of toll like receptor 9 in maintaining gut homeostasis. Ann Syst Biol 3(1): 010-014. 
3. Lee J, Mo JH, Katakura K, Alkalay I, Rucker AN, et al. (2006) Maintenance of colonic homeostasis by distinctive apical TLR9 signalling in intestinal epithelial cells. Nat Cell Biol 8: 1327-1336. Link: https://bit.ly/3dDC80n

4. Lee J, Gonzales-Navajas JM, Raz E (2008) The "polarizing-tolerizing" mechanism of intestinal epithelium: its relevance to colonic homeostasis. Semin Immunopathol 30: 3-9. Link: https://bit.ly/2USIhx9

5. Price AE, Shamardani K, Lugo KA, Deguine J, Roberts AW, et al. (2018) A Map of Toll-like Receptor Expression in the Intestinal Epithelium Reveals Distinct Spatial, Cell Type-Specific, and Temporal Patterns. Immunity 49: 560-575 e6. Link: https://bit.ly/2UEjAnP

6. Rehli M (2002) Of mice and men: species variations of Toll-like receptor expression. Trends Immunol 23: 375-378. Link: https://bit.ly/3dvh2kt

7. Marongiu L, Gornati L, Artuso I, Zanoni I, Granucci F (2019) Below the surface: The inner lives of TLR4 and TLR9. J Leukoc Biol 106: 147-160. Link: https://bit.ly/2Uncvcz

8. Sasai M, Linehan MM, Iwasaki A (2010) Bifurcation of Toll-like receptor 9 signaling by adaptor protein 3. Science 329: 1530-1534. Link: https://bit.ly/33NTyTn

9. Barton GM, Kagan JC, Medzhitov R (2006) Intracellular localization of Toll-like receptor 9 prevents recognition of self DNA but facilitates access to viral DNA Nat Immunol 7: 49-56. Link: https://bit.ly/2Jfx8Rz

10. Mouchess ML, Arpaia N, Souza G, Barbalat R, Ewald SE, et al. (2011) Transmembrane mutations in Toll-like receptor 9 bypass the requirement for ectodomain proteolysis and induce fatal inflammation. Immunity 35: 721-732. Link: https://bit.ly/2WLGQD2

11. Dlugosz A, Zakikhany K, Acevedo N, D’Amato M, Lindberg G (2017) Increased Expression of Toll-Like Receptors 4, 5 and 9 in Small Bowel Mucosa from Patients with Irritable Bowel Syndrome. BioMed Res Int 2017: 9624702. Link: https://bit.ly/39ITA65

12. Ghadimi D, Vrese M, Heller KJ, Schrezenmeir J (2010) Effect of natural commensal-origin DNA on toll-like receptor 9 (TLR9) signaling cascade chemokine IL-8 expression and barrier integritiy of polarized intestinal epithelial cells. Inflammatory bowel diseases 16: 410-427. Link: https://bit.ly/3buXv1K

13. Ewaschuk JB, Backer JL, Churchill TA, Obermeier F, Krause DO, et al. (2007) Surface expression of Toll-like receptor 9 is upregulated on intestinal epithelial cells in response to pathogenic bacterial DNA. Infection and immunity 75 : 2572-2579. Link: https://bit.ly/2xplalA

14. Zheng B, Morgan ME, van de Kant HJG, Garssen J, Folkerts G, et al. (2017) Transcriptional modulation of pattern recognition receptors in chronic colitis in mice is accompanied with Th1 and Th17 response. Biochem Biophys Rep 12: 29-39. Link: https://bit.ly/2UHGo5Y

15. Yuasa H, Mantani Y, Masuda N, Nishida M, Kawano J, et al. (2017) Differential expression of Toll-like receptor-2, -4 and -9 in follicle-associated epithelium from epithelia of both follicle-associated intestinal villi and ordinary intestinal villi in rat Peyer's patches. J Vet Med Sci 78: 1797-1804.

16. Kubinak JL, Round JL (2012) Toll-like receptors promote mutually beneficial commensal-host interactions. PLoS Pathog 8: e1002785. Link: https://bit.ly/2QOWzOy

17. Abreu MT (2010) Toll-like receptor signalling in the intestinal epithelium: how bacterial recognition shapes intestinal function. Nature reviews Immunology 10: 131-144. Link

18. Bleich A, Janus LM, Smoczek A, Westendorf AM, Strauch U, et al. (2009) CpG motifs of bacterial DNA exert protective effects in mouse models of IBD by antigen-independent tolerance induction. Gastroenterology 136: 278-287. Link: https://bit.ly/2UkBCww

19. Hiramatsu Y, Satho T, Irie K, Shiimura S, Okuno T, et al. (2013) Differences in TLR9-dependent inhibitory effects of $\mathrm{H}_{2} \mathrm{O}_{2}$-induced IL-8 secretion and
NF-kappa B/I kappa B-alpha system activation by genomic DNA from five Lactobacillus species. Microbes Infect 15: 96-104. Link: https://bit.ly/2Uygly4

20. Hotte NS, Salim SY, Tso RH, Albert EJ, Bach P, et al. (2012) Patients with inflammatory bowel disease exhibit dysregulated responses to microbial DNA. PLoS One 7: e37932. Link: https://bit.ly/3dwGR3N

21. Jijon $\mathrm{H}$, Backer J, Diaz H, Yeung $\mathrm{H}$, Thiel D, et al. (2004) DNA from probiotic bacteria modulates murine and human epithelial and immune function. Gastroenterology 126: 1358-1373. Link: https://bit.ly/3bsB6C9

22. Rachmilewitz D, Katakura K, Karmeli F, Hayashi T, Reinus C, et al. (2004) Tolllike receptor 9 signaling mediates the anti-inflammatory effects of probiotics in murine experimental colitis. Gastroenterology 126: 520-528. Link: https://bit.ly/2UGf87X

23. Rachmilewitz D, Karmeli F, Takabayashi K, Hayashi T, Leider-Trejo L, et al. (2002) Immunostimulatory DNA ameliorates experimental and spontaneous murine colitis. Gastroenterology 122: 1428-1441. Link: https://bit.ly/2wJ6mhw

24. Katakura K, Lee J, Rachmilewitz D, Li G, Eckmann L, et al. (2005) Toll-like receptor 9-induced type I IFN protects mice from experimental colitis. J Clin Invest 115: 695-702. Link: https://bit.ly/3dumhRH

25. Li Y, Liu M, Zuo Z, Liu J, Yu X, et al. (2017) TLR9 Regulates the NF-kappaBNLRP3-IL-1beta Pathway Negatively in Salmonella-Induced NKG2D-Mediated Intestinal Inflammation. J Immunol 199: 761-773. Link: https://bit.ly/33MzSzg

26. Hiramatsu Y, Sakamoto D, Satho T, Irie K, Miake F, et al. (2019) Lactobacillus plantarum induces genomic DNA-dependent and TLR9-mediated elafin secretion from Caco-2 cells. Asian Pac J Allergy Immunol 37: 36-42. Link: https://bit.ly/39qoCcW

27. Hofmann C, Dunger N, Doser K, Lippert E, Siller S, et al. (2014) Physiologic TLR9-CpG-DNA interaction is essential for the homeostasis of the intestinal immune system. Inflammatory bowel diseases 20: 136-143. Link: https://bit.ly/2UyfFJ2

28. Hemmi H, Takeuchi O, Kawai T, Kaisho T, Sato S, et al. (2000) A Tolllike receptor recognizes bacterial DNA. Nature 408: 740-745. Link: https://bit.ly/3aoXWKV

29. Suzuki MM, Bird A (2008) DNA methylation landscapes: provocative insights from epigenomics. Nat Rev Genet 9: 465-476. Link: https://bit.ly/2Q05ZsO

30. Ratel D, Ravanat JL, Berger F, Wion D (2006) N6-methyladenine: the othe methylated base of DNA. Bioessays 28: 309-315. Link: https://bit.ly/2JhK9Kr

31. Brencicova E, Diebold SS (2013) Nucleic acids and endosomal pattern recognition: how to tell friend from foe? Front Cell Infect Microbiol 3: 37. Link: https://bit.ly/3dAQDBN

32. Haas T, Metzger J, Schmitz F, Heit A, Muller T, et al. (2008) The DNA suga backbone 2' deoxyribose determines toll-like receptor 9 activation. Immunity 28: 315-323. Link: https://bit.ly/3br8sS7

33. Ohto U, Shibata T, Tanji H, Ishida H, Krayukhina E, et al. (2015) Structural basis of $\mathrm{CpG}$ and inhibitory DNA recognition by Toll-like receptor 9. Nature 520: 702 705. Link: https://go.nature.com/2UCW3Us

34. Wagner $\mathrm{H}$ (2008) The sweetness of the DNA backbone drives Toll-like receptor 9. Current opinion in immunology 20: 396-400.

35. Luther J, Owyang SY, Takeuchi T, Cole TS, Zhang M, et al. (2011) Helicobacte pylori DNA decreases pro-inflammatory cytokine production by dendritic cells and attenuates dextran sodium sulphate-induced colitis. Gut 60: 1479-1486 Link: https://bit.ly/2UnWT8k

36. Ohto U, Ishida H, Shibata T, Sato R, Miyake K, et al. (2018) Toll-like Recepto 9 Contains Two DNA Binding Sites that Function Cooperatively to Promote Receptor Dimerization and Activation. Immunity 48: 649-658 e4. Link: https://bit.ly/2JkLv6U

Citation: Varga MG, Lin HC (2020) The role of toll like receptor 9 in maintaining gut homeostasis. Ann Syst Biol 3(1): 010-014.

DOI: https://dx.doi.org/10.17352/asb.000005 
37. Suttle CA (2005) Viruses in the sea. Nature 437: 356-361. Link: https://bit.ly/3dy23pZ

38. Barr JJ, Auro R, Furlan M, Whiteson KL, Erb ML, et al. (2013) Bacteriophage adhering to mucus provide a non-host-derived immunity. Proc Natl Acad Sci U S A 110: 10771-10776. Link: https://bit.ly/2WIwiVn

39. Gogokhia L, Buhrke K, Bell R, Hoffman B, Brown DG, et al. (2019) Expansion of Bacteriophages Is Linked to Aggravated Intestinal Inflammation and Colitis. Cell Host Microbe 25: 285-299 e8. Link: https://bit.ly/2UlotfJ

40. O'Hara JR, Feener TD, Fischer CD, Buret AG (2012) Campylobacter jejuni disrupts protective Toll-like receptor 9 signaling in colonic epithelial cells and increases the severity of dextran sulfate sodium-induced colitis in mice. Infect Immun 80: 1563-1571. Link: https://bit.ly/3amdW09

41. Owyang SY, Luther J, Owyang CC, Zhang M, Kao JY (2012) Helicobacter pylor DNA's anti-inflammatory effect on experimental colitis. Gut microbes 3: 168 1671. Link: https://bit.ly/39jxkJX
42. Atreya R, Bloom S, Scaldaferri F, Gerardi V, Admyre C, et al. (2016) Clinical Effects of a Topically Applied Toll-like Receptor 9 Agonist in Active Moderate-to-Severe Ulcerative Colitis. J Crohns Colitis 10: 1294-1302. Link: https://bit.ly/2Jia30n

43. Gomes-Neto JF, Sartorius R, Canto FB, Almeida TS, Dias AA, et al. (2018) Vaccination With Recombinant Filamentous fd Phages Against Parasite Infection Requires TLR9 Expression. Frontiers in immunology 9: 1173. Link: https://bit.ly/3dzXPOv

44. Sartorius R, D'Apice L, Trovato M, Cuccaro F, Costa V, et al. (2015) Antigen delivery by filamentous bacteriophage fd displaying an anti-DEC-205 singlechain variable fragment confers adjuvanticity by triggering a TLR9-mediated immune response. EMBO Mol Med 7: 973-988. Link: https://bit.ly/2WNHksu

45. Hashiguchi S, Yamaguchi Y, Takeuchi O, Akira S, Sugimura K (2010) Immunological basis of M13 phage vaccine: Regulation under MyD88 and TLR9 signaling. Biochemical and biophysical research communications 402 19-22. Link: https://bit.ly/2UJBWUm

\section{Discover a bigger Impact and Visibility of your article publication with} Peertechz Publications

Copyright: @ 2020 Varga MG, et al. This is an open-access article distributed under the terms of the Creative Commons Attribution License, which permits unrestricted use, distribution, and reproduction in any medium, provided the original author and source are credited. 